\title{
A MULTI-CRITERIA DECISION MODEL FOR TURKISH SOFT DRINK INDUSTRY
}

\author{
Sebnem Burnaz, Y. Ilker Topcu \\ Istanbul Technical University, Management Faculty \\ ITU Isletme Fakultesi, \\ Macka 34367, Istanbul, TURKEY \\ ilker.topcu@itu.edu.tr
}

Keywords: ANP, soft drink, market share, consumer preference

Summary: This research is based on quantifying consumer preference in soft drink industry for a cola brand by using an integrated multi-criteria decision aid approach. The analytic network process model is used to conduct a comprehensive evaluation of the problem on hand. In accordance with the sequence of decision making process, after structuring the problem and constructing the decision model, a quantitative analysis is conducted in order to assess the importance of the related factors and predict the market shares of the key players in the industry. Predicted values are compared with actual ones for validation of the whole process. The assessed importance of the factors, in a valid model, would be a potential competitive advantage for the key players in the industry.

\section{Introduction}

Marketing involves all business functions that connect the producer to the consumer. Therefore, marketing planning includes issues of pricing; product design and performance to the extent that successful products must anticipate and meet consumer needs; physical distribution to the extent that the marketer must deliver the products to consumer where and when they want them; and promotion, which includes advertising and sales among other forms of marketing communication (Garber Jr., Hyatt, Starr Jr. 2003, p.7). That's why effective strategic marketing planning must consider and integrate all of the above elements, namely the marketing mix. As attributes (factors) that define products may include dimensions relevant to consumer preference, a multi-attribute decision model can provide a mean of incorporating elements of this marketing mix. Being aware of these factors and their relative importance would be a potential competitive advantage for producers.

Identifying the factors which influence the preference of a specific cola brand, defining the effects of these factors on each other, and assessing the importance of them from the Turkish consumers' point of view necessitate an effective decision making process. This study proposes an integrated Multi-Criteria Decision Aid (MCDA) based evaluation that executes such a process through the stages of structuring the problem, constructing the decision model, and analyzing the problem.

As a result of this decision making process, the importance of the related factors and the market shares of the key players in the industry are assessed. Predicted market share values are compared with actual ones for validation of the whole process. For this purpose, a special scale called as Saaty Compatibility Index (SCI) is calculated for checking the closeness of two priority vectors (www.creativedecisions.net). Here, the first priority vector is the predicted market shares and the second priority vector is the actual market shares. If SCI succeeds, one can rely on the relative importance of the related factors. Producers can use this information about what drives market share and can take actions to increase their company's market share. 


\section{The Beverage Industry in Turkey}

Turkish beverage industry is one of the leading industries in Turkey constituting an important portion of the country's GDP. Beverage industry can be divided into two different sub-markets: Alcohol free beverage market and alcoholic beverage market. The strengths of the industry are the size of the market due to the country's high population (especially high young population), dynamic private sector economy, substantial tourism income, and favorable climate (as drinks are generally consumed at hot weather). On the other hand the main problems of the beverage industry are the economic instability and legislation problems (high taxes and advertising bans) especially on the alcoholic beverage sector.

According to "Overview of Turkish Beverage Industry" (www.isikun.edu.tr/isam/diger_doc) report, Turkish per capita consumption of all beverages is currently only 263 liters, with the market traditionally dominated by tea. Other popular drinks are cola and ayran (diluted yogurt). Table 1 exhibits the details related to the beverages consumption in the country. As can be seen from Table 1, there is a decrease in consumption of commercial beverages. This is in accordance with the population's suffering enormously from the erosion of purchasing power in past years. Actually, the apparent reason of this decline is a series of financial crisis erupted in Turkey at and before this period. The return to positive economic growth in recent years had a much more muted effect on the commercial soft drinks market, which actually saw a very slight, drop in volume. It is therefore more realistic to assume that the recovery in the Turkish soft drinks market will be slow and will remain vulnerable to political/economic developments, and that carbonates, packaged water and juice/nectars will not regain their 2000 peaks before 2005 at the earliest.

Table 1. Commercial Beverage Consumption per Capita in Turkey

\begin{tabular}{lrrrrrr}
\hline Year & $\mathbf{1 9 9 8}$ & $\mathbf{1 9 9 9}$ & $\mathbf{2 0 0 0}$ & $\mathbf{2 0 0 1}$ & $\mathbf{2 0 0 2}$ & $\mathbf{2 0 0 3}$ \\
\hline Population (million) & 64.367 & 65.493 & 66.67 & 67.481 & 68.34 & 69.246 \\
\hline Volume (liters per capita) & & & & & & \\
All Commercial Beverages & 279 & 278.6 & 275 & 266.2 & 262.5 & 260 \\
Hot Drinks & 197.8 & 195.6 & 191.1 & 187.6 & 183.9 & 180.2 \\
$\quad$ Coffee & 4.8 & 4.6 & 4.5 & 4.5 & 4.5 & 4.5 \\
$\quad$ Tea & 193 & 191 & 186.6 & 183.1 & 179.4 & 175.7 \\
Soft Drinks & 50.8 & 52.3 & 53.1 & 47.9 & 47.2 & 47.8 \\
Milk/Milk drinks & 17.9 & 18.2 & 18 & 18.2 & 18.5 & 18.9 \\
Alcoholic drink & 12.5 & 12.5 & 12.8 & 12.5 & 12.9 & 13.1 \\
$\quad$ Beer & 10.4 & 10.4 & 10.8 & 10.6 & 11 & 11.2 \\
Wine & 0.7 & 0.7 & 0.7 & 0.6 & 0.6 & 0.6 \\
$\quad$ Spirits & 1.4 & 1.4 & 1.3 & 1.3 & 1.3 & 1.3 \\
\hline
\end{tabular}

Alcohol free beverage products in Turkish market are packaged water (sparkling and still), carbonates (colas, tonic/bitter drinks, other non-fruit flavors, orange, lemon-lime, clear lemonade and low calorie carbonates), fruit juice drinks/nectars, iced/ready-to-drink (rtd) tea and coffee drinks, non-rtd squash/syrups (liquid concentrates), fruit powders, sports drinks, and energy drinks. Above industries have different sizes within the industry. Since hot tea is very traditional and inexpensive in Turkey, the largest industry with respect to sales volume is non-rtd tea with approximately 2,100 million liters (www.isikun.edu.tr/isam/diger_doc). The following industries with large volume are carbonates (315 million liters) and water (171 million liters).

There are three major industry key players in Turkish cola industry: Coca-Cola Turkey (Coca-Cola), Pepsi Bottling Group (Pepsi-Cola), and Ulker Group (Cola-Turka). Coca-Cola first entered the Turkish market in 1965. Manufacturing has been rationalized in recent years, and is now concentrated on 5 plants. There are 5 regional warehouses. Production, sales and distribution are managed by Coca-Cola Icecek (CCI), formerly known as Coca-Cola Bottlers of Turkey (CCBT), which is a joint venture between TCCC (40\%), Anadolu Holding (also 40\%; Efes Pilsen, the largest brewer in Turkey, is one of the core businesses of this major industrial group) and the Ozgorkey Group (20\%). CCI manufacture and sell 
Coca-Cola, Fanta (fruit juice carbonate), and Cappy (juice nectar). The Pepsi Bottling Group, Inc. (PBG) completed the purchase of Fruko Mesrubat Pazarlama ve Ticaret (Fruko), the exclusive Pepsi bottler in Turkey, from the principal local owners and PepsiCo for approximately $\$ 100$ million in 2002 (www.isikun.edu.tr/isam/diger_doc). PBG acquired Fruko taking over Pepsi-Cola Icecek’s (PCI) 22\% stake and purchasing the remaining shares from Tamek Holding. Tamek Holding has held the exclusive rights to produce and distribute all PCI products, alongside with Fruko's own brands. Fruko used to manufacture and sell Pepsi-Cola, 7-Up, and a number of local brands of carbonates and juices. There are currently 6 major plants for carbonates. Ulker Group, on the other hand, operates in soft drinks categories - mainly carbonates and still fruit drinks, but also nectars, powdered fruit drinks, and iced tea. Ulker, fully owned by Ulker family, is a highly successful group, with origins in biscuits (clearly the market leader with $40 \%$ share) and chocolate confectionery (again the leader with 40\% share). Ulker probably has the best sales and distribution operation of any Turkish fast moving consumer goods (FMCG) company, with effective penetration of even the smallest rural outlets via a network of some 3000 wholesalers and some 400 service vans covering main cities. Its Atlas distribution arm is responsible for virtually all biscuits, confectionery and beverage lines and claims to reach over 200,000 outlets weekly.

Before the launch of Cola-Turka in July 2003, the market shares of the major players of the Turkish cola industry were $71.7 \%$ for Coca-Cola and $20.9 \%$ for Pepsi-Cola. Cola-Turka was launched with a huge marketing support in Turkish cold soft drink (CSD) market. Huge marketing support combined with robust distribution effort of Ulker Group resulted in 9.1\% market share at the first month of the launch. An important part of Cola-Turka strategic mix is its trade strategy. After Cola-Turka launch, trade negotiation power has increased against Coca-Cola. Besides that Cola-Turka payment terms are very flexible when compared to Coca-Cola (3 months vs. 21 days) and this condition negatively affected Coca-Cola Company products shares. Main weakness of Ulker in CSD market are insufficient marketing expertise, lack of know-how in CSD market, too crowded product portfolio, "Islamic Fundamentalist" image, autocratic management, being a family-owned company, and low profitability levels. After the launch of Cola-Turka, all brands and categories lost significant amount of market share. Pepsi-Cola is gradually losing market share since the launch of Cola-Turka and left its second place in the market to Cola-Turka. In August 2004, the market shares of the major players were $57.1 \%$ for Coca-Cola, $25.6 \%$ for Cola-Turka and $12.3 \%$ for Pepsi-Cola (www.procongfk.com.tr).

\section{Proposed MCDA Framework}

As quantifying the consumer preference in soft drink industry for a cola brand would have conflicting attributes and would necessitate a whole process of structuring, modeling, and analysis, it can be treated by an integrated MCDA based evaluation (Keeney 1996; Roy 1990; Stewart 1992; Vincke 1992; Yoon and Hwang 1995). Topcu (2000) proposed such an evaluation, called as Integrated Decision Aid (IDEA). IDEA was recently utilized in different decision-making situations (Тopcu and Ulengin 2004; Ulengin and Topcu 2003; Ulengin, Topcu, and Sahin 2001). Integrated MCDA based evaluation provides a structural method for incorporating the information, opinions, and preferences of the relevant people into the decision making process and this process integrates all the stages: structuring the problem, constructing the decision model, and analyzing the decision problem.

The first stage of the proposed approach aims eliciting the executive knowledge, opinion, and expertise that might be relevant to the problem. For this purpose, there are alternative approaches that can be executed. A questionnaire survey can be conducted using a Delphi type group decision-making procedure (Hwang and Lin 1987). During Delphi procedure, a small monitor team acting as decision analysts designs a questionnaire that will be sent (via fax or by e-mail) to a larger group of respondents. The questionnaire is filled and returned by the experts (professionals and/or academicians). The monitor team, then, evaluates judgments and consolidates the results, develops a new questionnaire for eliciting new judgments from the respondent group. The process continues until all factors are determined (Lee and Kim 2001). Another approach is literature review. The previous studies and researches on the problem under consideration can be used as secondary sources and are reviewed in order to reveal the related 
factors on the subject. Third approach; on the other hand, is using a decision structure which is used somewhere else before. Especially, global problems are appropriate for this kind of treatment.

The second stage of the proposed framework starts with finding a suitable form of decision model for the list of identified factors (attributes) in order to have a manageable decision environment that can be examined. If there is no relationship between factors and they can not be classified in groups; a decision matrix, having alternatives at rows, factors at columns, and performance values of alternatives with respect to factors at the entries, can be utilized. If there are many factors and they can be classified into some form of association or grouping; decision hierarchy (Figure 1a), decomposing the information relevant to the problem to the levels and having alternatives at the bottom level, can be utilized. If there are dependencies and feedback among the factors; the former two forms would not be appropriate for modeling the problem. In this case, decision network (Figure 1b) can be utilized. Analytic Network Process (ANP) approach, proposed by Saaty (1996), can be utilized for examining both hierarchy and network model representations. The power of ANP lies in its use of special ratio scales (Saaty 1980) to capture all kinds of interactions for making accurate predictions and better decisions. In the ANP approach, the factors affecting the decision are cast into a multi level hierarchical network. Relationships can exist among factors of this network both within a level as well as among levels. So far, ANP approach has proven itself to be a success when expert knowledge is used within business (Agarwal and Shankar 2002; Lee and Kim 2000; Lee and Kim 2001; Meade and Sarkis 1998; Partovi 2001; Sarkis and Sundarraj 2002; Sarkis and Talluri 2002), social (Sarkis 1998; Sarkis 1999; Sarkis 2003), and manufacturing (Karsak, Sozer, and Alptekin 2003; Meade and Sarkis 1999) decision contexts or used to predict sports outcomes (Partovi and Corredoira 2002) and economic turns (Blair et al., 2002).

Figure 1. A Hierarchy and a Network Sample

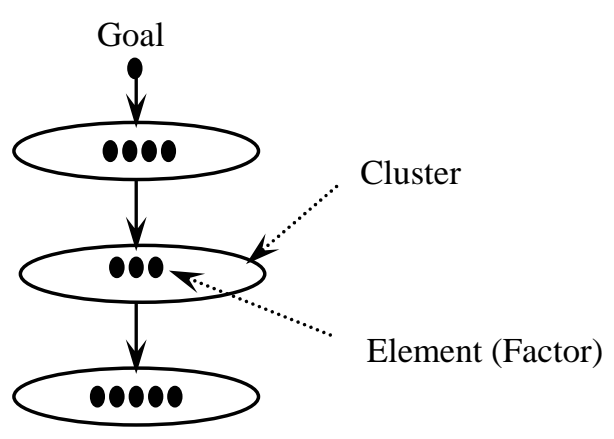

1.a.

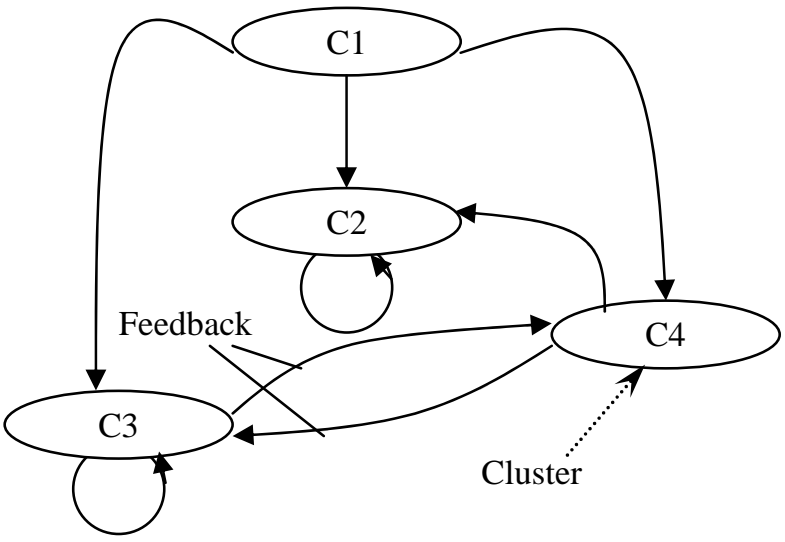

1.b.

In the proposed approach, the experts are asked via a new questionnaire to indicate the relationship between pairs of these factors. Monitor team fills pairwise relationship matrices by using the responses of the experts. The entries of the matrix represent the value of the direct relationship from concept factor $i$ to concept factor $j$. The entries $a_{i j}$ can take the values of 1,0 or -1 ( $a_{i j}=1$ if positive relationship from $i$ to $j$ is present in the cognitive map; $a_{i j}=-1$ if a negative relationship exists, and $a_{i j}=0$ in case of no relationship). Monitor team, then, aggregates these matrices into a single matrix, where a level of $60 \%$ was considered as a minimum requirement for the entry. By utilizing graph theory, the aggregated matrix can easily be converted to a signed digraph. At the signed digraph, nodes represent factors and arcs between these nodes represent relationship between the factors. The existence of dependencies and feedback among the identified factors reveal the suitable model for the problem on hand as hierarchy or network form. In accordance with this finding, as a further step of the second stage, the monitor team elicits the decision makers' judgments, which reflect ideas, feelings, and emotions of them. Soft drink consumers constituted the sample of decision makers. The sampling procedure of the survey lies heavily on convenience sampling. The decision makers are asked to make pairwise comparisons of the factors of the network using a nine-point scale suggested by Saaty (1980): "of the sub-nodes, which one influences 
the parent node more and how much more?" or "of the dependent factors, which one influences the common factor more and how much more?". In this scale, a value of 1 between two factors indicates that both are equally influencing the parent node, whereas a value of 9 indicates that influence of one factor is extremely more than that of the other. A pairwise comparison questionnaire survey is conducted in order to assess the consumers' judgments representing the relative influence (importance) of sub-nodes on (with respect to) their parent node for all possible pairs. At the final step of this stage, the elicited judgments of different consumers are aggregated. The monitor team computes the geometric means of all paired comparison judgments for each question in order to reveal the aggregated group judgments. Group judgments are, then, arranged in pairwise comparison matrices which will be input for Super Decisions software (www.superdecisions.com). In the aggregated pairwise comparison matrix, the value for an ( $i$, $j$ )-pair is in the range $1-9$ if the influence of factor $i$ is more than that of the factor $j$, while the value of that pair is in the range $1-1 / 9$ if the influence of factor $i$ is less than that of the factor $j$. Nevertheless, the value of an $(i, i)$ pair is 1 and given the $(i, j)$-value, the corresponding $(j, i)$-value is the reciprocal.

The relative importance of the factors is computed at the third stage. The importance can be regarded as the influence of the factors to the goal (consumer preference for cola brand). For this purpose, necessary calculations, in order to synthesize aggregated judgments, are done by Super Decisions software. These calculations include the computation of eigenvector for each pairwise comparison matrix, the formation of a supermatrix and a weighted supermatrix (if necessary), and the computation of the convergence of the supermatrix (limit matrix). The eigenvector consists of priorities of the sub-nodes with respect to their parent node (Saaty 1980). The easiest way for the computation of eigenvector starts with the normalization of the pairwise comparison matrix - dividing each element by its column sum - so that each column adds to one. The arithmetic mean (average) of the values of each row is an element of the eigenvector. In a supermatrix, each is represented at one row and one respective column (i.e. the goal is at the first row and first column). The computed eigenvector of the sub-nodes with respect to their parent node is placed to the column representing the parent node and the rows representing the sub-nodes. If the column sum of any column in the composed supermatrix is greater than 1 (there are more than one eigenvector), that column will be normalized. Such a supermatrix is called as weighted supermatrix. The weighted supermatrix is then raised to a significantly large power in order to have the converged or stable values. The values of this limit matrix (importance of related factors and predicted market shares) are the desired priorities of the elements of the decision network with respect to the goal.

Predicted market share values can be compared with actual ones for validation of the whole process. As aforementioned, a special scale called as Saaty Compatibility Index (SCI) is calculated for checking the closeness of two priority vectors. In other words, SCI is used to find how close market share estimations using ANP are to actual data. Two pairwise comparison matrices are generated from the priority vectors representing the estimated market share data and actual market share data: pairwise comparison matrix from actual data and transpose of comparison matrix from estimations. Hadamard (cell-wise) multiplication of these two comparison matrices is calculated. The sum of the row sums of this resulting matrix is divided to the number of entries. The calculated value is SCI (See Figure 2 for details). If the SCI is near to 1 , it means that the ANP model is valid and therefore one can rely on the importance of the related factors at the model.

\section{Utilization of the Proposed Model}

The proposed MCDA framework was utilized in order to assess the importance of these factors from consumers' point of view and predict the market shares of the key players in the industry. These purposes necessitate the execution of the all stages of an effective decision making process.

First of all, as the key players in Turkish soft drink industry are global brands and authors have a sample ANP model available for Super Decisions software (www.superdecisions.com), the authors selected the third approach mentioned at Section 3.1. 
Figure 2. SCI Calculation

\begin{tabular}{|c|c|c|c|c|}
\hline Vector of actual data & & Pairwi & omparis & matrix \\
\hline A1 & & A1/A1 & A1/A2 & A1/A3 \\
\hline A2 & & A2/A1 & $\mathrm{A} 2 / \mathrm{A} 2$ & A2/A3 \\
\hline A3 & & A3/A1 & A3/A2 & A3/A3 \\
\hline Vector of estimations & & Transpos & f compa & on matri \\
\hline B1 & & B1/B1 & B2/B1 & B3/B1 \\
\hline B2 & 7 & B1/B2 & B2/B2 & B3/B2 \\
\hline B3 & & B1/B3 & B2/B3 & B3/B3 \\
\hline
\end{tabular}

Hadamard multiplication
$\mathrm{A} 1 / \mathrm{A} 1 * \mathrm{~B} 1 / \mathrm{B} 1$
$\mathrm{A} 1 / \mathrm{A} 2 * \mathrm{~B} 2 / \mathrm{B} 1$
$\mathrm{A} 1 / \mathrm{A} 3 * \mathrm{~B} 3 / \mathrm{B} 1$
$\mathrm{A} 2 / \mathrm{A} 1 * \mathrm{~B} 1 / \mathrm{B} 2$
$\mathrm{A} 2 / \mathrm{A} 2 * \mathrm{~B} 2 / \mathrm{B} 2$
$\mathrm{A} 2 / \mathrm{A} 3 * \mathrm{~B} 3 / \mathrm{B} 2$
$\mathrm{A} 3 / \mathrm{A} 1 * \mathrm{~B} 1 / \mathrm{B} 3$
$\mathrm{A} 3 / \mathrm{A} 2 * \mathrm{~B} 2 / \mathrm{B} 3$
$\mathrm{A} 3 / \mathrm{A} 3 * \mathrm{~B} 3 / \mathrm{B} 3$

\section{Row Sums}

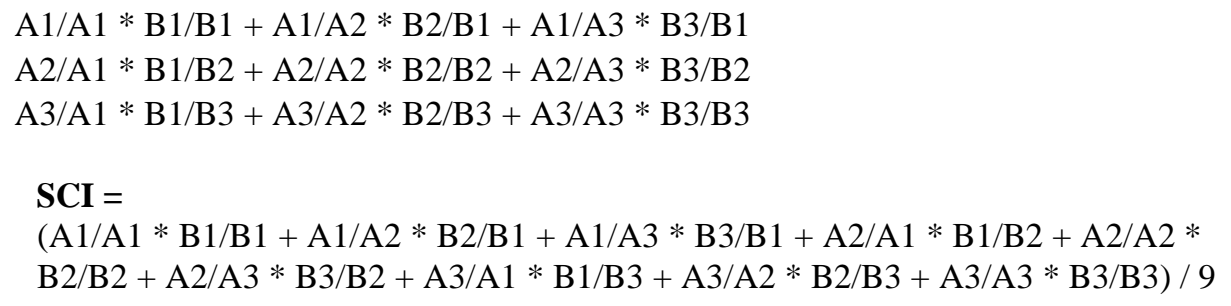

The factors of the sample ANP model have been taken into consideration:

PRODUCT RELATED

- Quality of depth

- Quantity of depth

- Taste acceptance

- Reputation

- Global reach

PROMOTION RELATED

- Frequency of advertising

- The current impact of advertising

- The historical impact of advertising

PLACE RELATED

- Restaurants

- Stores

- Machines

The experts (marketing professionals of the industry) were asked via a questionnaire to indicate the relationship between pairs of these factors. As aforementioned monitor team filled pairwise relationship matrices by using the responses of the experts and then, aggregated these matrices into a single matrix. Finally, the aggregated matrix was converted to a signed digraph. The dependencies and feedback among the identified factors revealed that the most suitable model for the problem on hand was network form. So the monitor team constructed the network model utilizing the design module of the Super Decisions software (Figure 3). 
Figure 3. The Analytic Network Model of the Problem

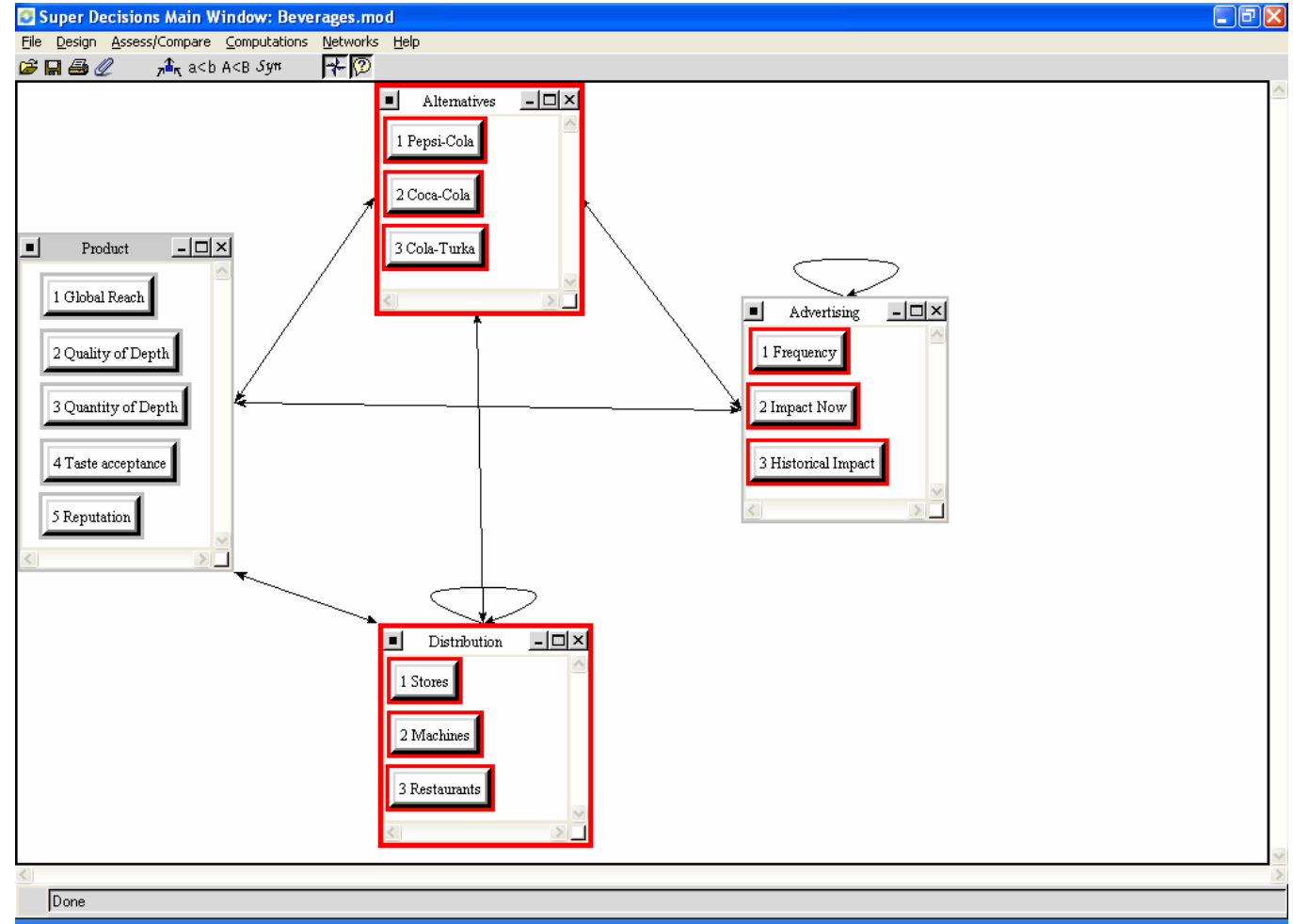

A pairwise comparison questionnaire, a part of which can be seen at Figure 4, was sent to the consumers in order to assess their judgments representing the relative influence of subnodes on the parent node for all possible pairs. Monitor team computed geometric means of all paired comparison judgments for each question in order to reveal the aggregated group judgments. And then, utilizing the assess/compare module of the Super Decisions software, the team arranged these group judgments in pairwise comparison matrices.

Figure 4. A Part of Pairwise Comparison Questionnaire

\begin{tabular}{l}
\hline With respect to goal "Consumer Preference for Cola Brand"; compare the relative importance of the factors given below \\
\hline
\end{tabular}

At the final stage of the decision making process, the relative importance of the factors were computed utilizing the computations module of the same ANP software which does all the matrix algebra. The output of the limit matrix can be converted to the descending priority (market shares of alternatives and importance of factors) orders (Table 2). As can be seen in Table 2, the estimated market shares of three key players (alternatives of the ANP model) in Turkish cola industry are 54\% for Coca-Cola, 31.9\% for Cola-Turka, and $14.1 \%$ for Pepsi-Cola. The actual market shares for these brands are 57.1\%, 25.6\%, and $12.3 \%$, respectively as given in Section 2 . Due to the fact that there are other brands with a total market share of $5 \%$, the total of actual market shares of three major brands are $95 \%$. If we try to find how close the estimations of ANP model are to actual data, we should first normalize the actual data to have it sum to 1 . When divided by $95 \%$, the normalized actual data can be calculated as $60 \%, 27 \%$, and $13 \%$. The closeness of these two vectors $(54 \%, 31.9 \%, 14.1 \%)$ and $(60 \%, 27 \%, 13 \%)$ can be found with SCI as 
aforementioned. The resulting value 1.01, which is very close to 1 , indicates that the ANP model was valid and therefore one can rely on the importance of the related factors at the model.

Table 2. The Importance of the Factors

\begin{tabular}{llr}
\hline Cluster & Element & Priority \\
\hline Alternatives & Coca-Cola & $54.0242 \%$ \\
& Cola-Turka & $31.9253 \%$ \\
& Pepsi-Cola & $14.0505 \%$ \\
\hline Product & Global Reach & $38.7462 \%$ \\
& Reputation & $37.3627 \%$ \\
& Quantity of Depth & $13.3116 \%$ \\
& Quality of Depth & $6.7452 \%$ \\
& Taste acceptance & $3.8344 \%$ \\
\hline Advertising & Frequency & $36.8730 \%$ \\
& Impact Now & $34.8360 \%$ \\
& Historical Impact & $28.2910 \%$ \\
\hline Distribution & Stores & $62.0729 \%$ \\
& Restaurants & $24.8682 \%$ \\
& Machines & $13.0589 \%$ \\
\hline
\end{tabular}

Regarding to priorities in Table 2, global reach and reputation can be regarded as more important than other product related factors. The most important channel for placement should be stores while frequency and current impact of advertising are the factors that are more important than past impact of advertising. Being aware of these important factors and emphasizing these factors during marketing operations can be a potential competitive advantage for the players in cola industry.

\section{Conclusions and Further Suggestions}

This paper describes a full, real world application of a MCDA framework dealing with the consumer preference in soft drink industry for a cola brand. The proposed framework is stated as a generic framework defining the effects of these factors on each other and assesses the importance of them from the consumer' point of view. As it is generic, it can also be utilized in other soft drinks and beverage industries as well as in other markets by implementing the same stages of the decision process.

For the structuring stage, the literature review lacks relevant studies. That's why second approach is omitted. A major flaw of the study, on the other hand, can be not using the first approach (identifying the factors which influence the preference based on executive knowledge, opinion, and expertise of professionals/academicians). But as the problem is global and there is a sample model available, this model is used. In order to have this study include the dynamics of Turkish soft drink industry, the relations between the factors of the sample model are elicited from the experts. The motive of executing the decision process as explained in the paper is having a valid model (SCI=1.01). Similarly the consumers can be used at the first and second stages of the decision process for identifying the relevant factors and relations among them. Although this would be a hard-to-explain and time consuming step, the comparison of results with the current study can be interesting.

As a future research, this framework can also be utilized for the same industry in other countries and cross cultural differences can be revealed. Another research avenue can be taking consumers who do not drink this kind of beverages as decision makers at the second stage of the framework and the importance of factors with respect to their judgments can be compared with the importance of factors that have been assessed by taking the customers of that product group as decision maker. So the players in the industry can understand which factors are important for non- buyers. 


\section{References}

Agarwal, A. and Shankar, R. (2002) "Analysing alternatives for improvement in supply chain performance.” Work Study 51, 32-37.

Blair, A.R., Nachtmann, R., Saaty, T.L. and Whitaker, R. (2002) "Forecasting the resurgence of the US economy in 2001: an expert judgement approach.” Socioeconomic Planning Sciences 36, 77-91.

Garber, L.L. Jr., Hyatt, E.M. and Starr Jr. R.G. (2003) “Measuring consumer response to food products.” Food quality and Preference 14, 3-15.

Hwang, C.L. and Lin, M.J. (1987) Group decision making under multiple criteria. Heidelberg: SpringerVerlag.

Karsak, E.E., Sozer, S. and Alptekin, S.E. (2003) "Production Planning in quality function deployment using a combined analytic network process and goal programming approach.” Computers and Industrial Engineering 44, 171-190.

Keeney, R.L. (1996) Value focused thinking: A path to creative decision making. London: Harvard University Press.

Lee, J.W. and Kim, S.H. (2000) "Using analytic network process and goal programming for interdependent information system project selection.” Computers \& Operations Research 27, 367-382.

Lee, J.W. and Kim, S.H. (2001) "An integrated approach for interdependent information system project selection.” International Journal of Project Management 19, 111-118.

Meade, L. and Sarkis, J. (1998) "Strategy analysis of logistics and supply chain management systems using the analytical network process." Transportation Research E: The Logistics and Transportation Review 34(3), 51-65.

Meade, L. and Sarkis, J. (1999) “Analyzing organizational project alternatives for agile manufacturing processes: an analytical network approach.” International Journal of Production Research 37, 241-261.

Partovi, F.Y. (2001) “An analytic model to quantify strategic service vision.” International Journal of Service Industry Management 12, 476-499.

Partovi, F.Y. and Corredoira, R.A. (2002) "Quality function deployment for the good of soccer." European Journal of Operational Research 137, 642-656.

Roy, B. (1990) “Decision aid and decision making”. Ed. Bana E Costa CA. Readings in Multiple Criteria Decision Aid. Heidelberg, Springer-Verlag, 17-35.

Saaty, T.L. (1980) Multicriteria decision making: The analytic hierarchy process. Pittsburg: RWS Publications.

Saaty, T.L. (1996) Decision making with dependence and feedback: The Analytic Network Process. Pittsburgh: RWS Publications,

Sarkis, J. (1998) “Evaluating environmentally conscious business practices.” European Journal of Operational Research 107, 159-174.

Sarkis, J. (1999) “A methodological framework for evaluating environmentally conscious manufacturing programs.” Computers \& Industrial Engineering 36, 783-810. 
Sarkis, J. (2003) “A strategic decision framework for green SCM.” Journal of Cleaner Production 11(4), 397-409.

Sarkis, J. and R.P. Sundarraj. 2002. "Hub location at digital equipment corporation: A comprehensive analysis of qualitative and quantitative factors.” European Journal of Operational Research 137, 336347.

Sarkis, J. and Talluri, S. (2002) “A synergic frame for evaluating business process improvements.” The International Journal of Flexible Manufacturing Systems 14, 53-71.

Stewart, T.J. (1992) "A critical survey on the status of MCDM theory and practice.” Omega 20 (5-6), 569-586.

Topcu, Y.I. (2000) "Integrated decision aid model for multiattribute problem solving.” Dissertation, Istanbul Technical University.

Topcu, Y.I. and Ulengin, F. (2004) "Energy for the future: An integrated decision aid for the case of Turkey.” Energy 29(1), 137-154.

Ulengin, F and Topcu, Y.I. (2003) "New paradigm in OR." Proceedings of Promoting Ethics in OR, April 25-26, INSEAD, Fontainebleau, 20-27.

Ulengin, F., Topcu, Y.I. and Sahin, S.O. (2001) "An artificial neural network approach to multicriteria model selection.” Lecture Notes in Economics and Mathematical Systems 507, 101-110.

Vincke, Ph. (1992) Multi criteria decision aid. West Sussex: John Wiley \& Sons, Inc.

Yoon, K.P and Hwang, C-L. (1995) Multi attribute decision making: An introduction. Sage University Papers Series, Quantitative Applications in the Social Sciences, No 07-104, London: Sage Pubn..

http://www.procongfk.com.tr (The website of Procon GFK Turkey Marketing Research Company)

http://www.creativedecisions.net (The website for Creative Decisions Homepage).

http://www.isikun.edu.tr/isam/diger_doc (Overview of Turkish Beverage Industry, Isik University, Political Informatics Division).

http://www.superdecisions.com (The website for Super Decisions Software for Decision Making). 